\title{
Soot in the Lubricating Oil: An Overlooked Concern for the Gasoline Direct Injection Engine?
}

Sebastian A. Pfau, Antonino La Rocca, Ephraim Haffner-Staton, Graham A. Rance, Michael W. Fay, and

Michael McGhee University of Nottingham

Citation: Pfau, S.A., La Rocca, A., Haffner-Staton, E., Rance, G.A. et al., "Soot in the Lubricating Oil: An Overlooked Concern for the Gasoline Direct Injection Engine?,” SAE Technical Paper 2019-01-0301, 2019, doi:10.4271/2019-01-0301.

\section{Abstract}

ormation of soot is a known phenomenon for diesel engines, however, only recently emerged for gasoline engines with the introduction of direct injection systems. Soot-in-oil samples from a three-cylinder turbocharged gasoline direct injection (GDI) engine have been analysed. The samples were collected from the oil sump after periods of use in predominantly urban driving conditions with start-stop mode activated. Thermogravimetric analysis (TGA) was performed to measure the soot content in the drained oils. Soot deposition rates were similar to previously reported rates for diesel engines, i.e. $1 \mathrm{wt} \%$ per $15,000 \mathrm{~km}$, thus indicating a similar importance. Morphology was assessed by transmission electron microscopy (TEM). Images showed fractal agglomerates comprising multiple primary particles with characteristic core-shell nanostructure. Furthermore, large amorphous structures were observed. Primary particle sizes ranged from 12 to $55 \mathrm{~nm}$, with a mean diameter of $30 \mathrm{~nm}$ and mode at $31 \mathrm{~nm}$. Particle agglomerates were measured by nanoparticle tracking analysis (NTA). The agglomerates were found to range between 42 and $475 \mathrm{~nm}$, with a mean size of $132 \mathrm{~nm}$ and mode at $100 \mathrm{~nm}$. The distribution was shifted towards larger sizes with a minor concentration of very large agglomerates observed around $382 \mathrm{~nm}$. While deposition rate and agglomerate morphology were similar to diesel engines, distinctive amorphous carbon and smaller particles were observed. Hence, existing knowledge for diesel applications might not be directly transferrable.

\section{Introduction}

ormation and emission of particulate matter, also known as soot, is a well-known phenomenon for diesel engines. Particulate filters and special oil formulations have been developed over the years to deal with this issue. With increasing efforts to optimise engines, direct injection systems are nowadays also used for gasoline engines instead of port fuel injection (PFI) systems [1]. However, the literature to date on this issue is relatively limited. A brief systematic literature search of articles on Web of Science, dated 31.12.2018, revealed significant difference in research coverage. $\frac{1}{}$ For diesel engines 1817 articles were found, whereas only 134 articles were found for gasoline direct injection (GDI) engines - the

\footnotetext{
${ }^{1}$ To specify the general field of interest, three relevant terms were selected to filter the document names: "(soot OR particulate matter OR partic* emission $\left.^{\star}\right)$ ". These terms were assumed to cover a range of the used terminology. For diesel direct injection compression ignition (CI) engines, the term "(diesel OR "compression ign ${ }^{\star}$ OR ci engine ${ }^{\star}$ )" was added by logical conjunction, i.e. AND operator. For gasoline direct injection spark injection (GDI/DISI) engines, the term "(gasoline direct inject* OR gdi OR disi OR spark ign ${ }^{\star}$ " was used. The search gasoline port fuel injection spark ignition (PFI) engines was conducted by using the term "(port fuel inject* OR pfi)". Only documents of type "article" included.
}

same value as for diesel engines in the year 1991. For PFI engines, an even smaller number of 15 articles was found. While $50 \%$ of papers on diesel soot were published before 2010 , nearly $95 \%$ of papers on GDI soot were published after 2010. No papers on PFI soot were found dating before 2012. The data highlights the relatively young age of the field of research. As port fuel injection gasoline engines generally show lower particulate matter emissions $[2, \underline{3}]$, the topic only became noticed and relevant after the introduction of GDI engines.

Soot generally forms under non-stoichiometric, fuel rich conditions. In the case of internal combustion engines, soot formation occurs if the fuel is not sufficiently mixed with air within the combustion chamber $[\underline{4}, \underline{5}]$. Of the initially formed radical species, acetylene is generally considered to be the most important precursor to the further formation process of soot [6]. Subsequent polymerisation reactions between these radicals yield small aromatic molecules, and eventually extended polycyclic aromatic hydrocarbons (PAH). Inception of particle phase soot species occurs at molecule diameters of approximately $1.5 \mathrm{~nm}[\underline{6}]$. The growth of such species continues by addition of vapour phase radicals, to form so called 'primary particles' with typical diameters of 10-50 $\mathrm{nm}$ [?] .

(c) 2019 The Authors. Published by SAE International. This Open Access article is published under the terms of the Creative Commons Attribution License (http:// creativecommons.org/licenses/by/4.0/), which permits distribution, and reproduction in any medium, provided that the original author(s) and the source are credited. 
These particles exhibit a core-shell nanostructure, consisting of an amorphous core and surrounding graphitic layers. Agglomeration of primary particles results in characteristic fractal structures. The size of particles and agglomerates can be affected by the environmental conditions [] ], i.e. conditions in the combustion chamber or cylinder. Operating conditions directly influence such environment, with engine speed and air/fuel-ratio showing particularly strong effects []․ High exhaust gas temperatures can lead to reductions in particulate size by oxidisation [6]. However, this effect can be cancelled out by antagonistic impact of the high loads necessary to cause high exhaust gas temperatures [9].

Uy et al. [10] observed structural similarities between diesel and GDI soot from both exhaust and lubricating oil. However, GDI soot also exhibited "sludge-like" regions with less distinctive particle borders and amorphous carbon. Similar observations were reported by An et al. [11], with the addition of multiple cores at the centre of the primary particles. Gaddam and Vander Wal [12] measured the visible nanostructure and obtained similar values for GDI soot as for diesel soot. On the contrary, Liati et al. [13] reported GDI soot to be less ordered, i.e. less graphitic. A comparative study by Pfau et al. [14] confirmed such differences, by identifying a decreasing structural order from carbon black to diesel and GDI soot. The specific nanostructure can not only affect the reactivity of soot [15] but also impede the effectiveness of oil additives as established by Esangbedo [16]. The latter was assumed to be caused by different interactions between the oil dispersants and the surface of the soot particles. The size of particles can affect the extent of implication on the human body, i.e. deposition in the respiratory tract $[\underline{17}, \underline{18}]$. As noted by Pedata et al. [19] the area of sub $10 \mathrm{~nm}$ particles was covered only scarcely to date. As such particles could even transfer from initial deposition in the lungs to the blood stream [20], the impact on the human health could be significant. In addition to the impact on human health and reactivity, the size of soot agglomerates as well as primary particles can influence the wear in engines.

As soot transfers into the lubricating oil, it increases the effective viscosity of the oil, i.e. oil thickening [16]. Lahouij et al. [21] confirmed the presence of strong cohesive forces between soot particles and their resistance to loading. Accumulation of soot can further lead to oil starvation and consequently wear due to metal-metal contact. Various studies have shown that soot accumulation in the lubricating

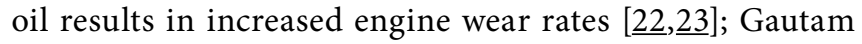
et al. [24] reported that wear increases with higher soot concentration. Furthermore, soot can compromise the effectiveness of anti-wear additives. The resulting wear effect is more pronounced for thin oil films, i.e. with thickness close to or smaller than the particle size $[\underline{22}, \underline{25}]$. This issue can be critical for the timing chain, as wear between pins and bushings leads to chain elongation [26]. Thickening of the oil results in pumpability issues due to the altered viscosity [27]. Higher levels of oil viscosity in a Mack-7 engine were found to stem from increased concentration as well as size of soot particles [28]. Berbezier et al. [29] assessed the effect on wear of carbon blacks with different primary particle sizes. With increasing particle size, both the wear rate increased, and the anti-wear properties of the oil were reduced. Similarly,
Mainwaring [30] observed more aggressive wear behaviour of soot with higher primary particle sizes. Li et al. [23] observed abrasive wear, with wear scar widths closely matching the size of primary particles. In a subsequent study on oil thickening, Bardasz et al. [31] observed improvements of oil viscosity due to higher soot amounts in some instances, while in other cases the viscosity was decreased as the amount of soot decreased. The oil samples further showed different soot size distributions. To account for both the size distribution and the amount of soot, a direct correlation between oil viscosity and surface area of the soot-in-oil particles was suggested.

Thermogravimetric analysis (TGA) is a commonly used technique to assess the content of soot in used lubricating oil samples. As such the sample has to be deconvoluted in its individual components: Organic volatiles, combustible matter (i.e. soot) and non-reactive ash $[10, \underline{32}, \underline{33}]$. This process is facilitated by measuring the change in mass while altering both temperature and gas environment in the chamber. While the specific protocols vary, two underlying principles remain consistent. Initial heating of the sample in an inert gas, such as nitrogen, enables desorption of volatile components from the sample, while preventing any simultaneous oxidation [34]. Subsequent use of air or oxygen allows for a controlled oxidation of the combustible compounds, i.e. residual soot. Clague et al. [32] assessed exhaust soot samples with soot extracted from lubricating oil for the same engines. In contrast to the study by Yehliu et al., the samples were heated to $650{ }^{\circ} \mathrm{C}$ in a nitrogen environment and then further to $750{ }^{\circ} \mathrm{C}$ in oxygen. The results showed differences between carbon-ash-volatile contents for the same source, indicating a change between exhaust soot to soot-in-oil. However, the extraction process appeared to alter the observed results. Yehliu et al. [35] assessed the impact of fuel formulations on the properties of exhaust soot from diesel engines. The study showed differences in the fraction of volatiles as well as oxidation rates. To reflect the conditions in vehicle applications, i.e. regeneration of particulate filters, the parameters for the TGA differed. As such, the samples were oxidised at $550{ }^{\circ} \mathrm{C}$ after preheating in a nitrogen environment $500^{\circ} \mathrm{C}$. Such protocol is in line with works of Mullins and Truhan [흐] as well as Bredin et al. [34], reducing the maximum temperature for the initial stage to avoid oxidation due to oxygen traces. Aside from compositional details, information on soot concentration is important for automotive applications as the amount of soot in the lubricating oil is linked to the extent of wear $[\underline{22}, \underline{25}, \underline{37}]$. Thus, the rate of deposition for engines is fundamental for recommendations of oil change intervals. Lockwood et al. [38] collected samples from three diesel engines operated under on-road conditions of five tracks. They observed a linear correlation between oil mileage and soot content with $\mathrm{R} 2=0.8$. However, no deposition rates were derived and no information on the TGA protocol included. Di Liberto et al. [39] analysed 15 soot-in-oil samples from 10 vehicles with diesel engines. The oil mileage of the samples ranged from $3320 \mathrm{~km}$ to $23386 \mathrm{~km}$, and a modified version of the ASTM D5967 test method was employed. The engines exhibited an overall deposition rate of $1 \mathrm{wt} \%$ per $15000 \mathrm{~km}$ with a standard deviation of $0.4 \mathrm{wt} \%$ - representing as such the first reference. Sharma et al. [40] also assessed diesel 
soot-in-oil with the ASTM D5967 method. The sample contained $1.78 \mathrm{wt} \%$ soot after 12798 miles, equivalent of a rate of $1.3 \mathrm{wt} \%$ per $15000 \mathrm{~km}$ and thus within reference. $\mathrm{Uy}$ et al. [10] measured soot-in-oil samples of both diesel and GDI engines. The TGA protocol involved heating to $650^{\circ} \mathrm{C}$ in nitrogen, before switching to air for an isothermal hold at the same temperature. The diesel sample showed higher soot content, however, no information on mileage was provided and thus no correlation was possible.

The measurement of agglomerates represents a complex challenge due to their fractal geometrical nature. Different approaches have been used across studies, mostly relying on two-dimensional projections in the form of transmission electron microscopy (TEM) images. Common parameters include the radius of gyration $[\underline{41}, \underline{42}]$ as well as skeleton width and length $[\underline{43}, \underline{4}]$. Although these methods enable the quantitative description of agglomerates, they do not represent the whole three-dimensional, fractal shape of the agglomerates and tend to overestimate the size [45]. In contrast, electron tomography can be used to reconstruct the actual volume of particles $[\underline{46}, \underline{47}]$. However, despite recent progress towards throughput optimisation [48], such procedure is still very time and cost intensive. For the in-situ analysis of particulates in the exhaust gas stream, scanning mobility particle sizers are commonly used $[\underline{49}, \underline{50}, \underline{51}]$. Analysis of soot-in-oil samples adds further complexity, usually requiring the removal of the particles from the lubricating oil. However, nanoparticle tracking analysis (NTA) has been shown to be an effective alternative [52]. To enable the particle analysis, the soot-laden oil has only to be diluted with a suitable agent, such as heptane. Thus, particle density in the dilution as well as its viscosity is reduced.

Primary particles within agglomerates can be measured directly from TEM images. Lee et al. [53] collected soot from the exhaust gas of a light duty diesel engine. The primary particle diameters ranged $10-60 \mathrm{~nm}$, with mean diameters of 28-34 $\mathrm{nm}$ depending on the operating conditions. In a subsequent study of Zhu et al. [42] with a different engine, the same diameter range and similar mean diameters of $19-33 \mathrm{~nm}$ were observed. Similarly, Neer and Köylü [9] observed primary particles of mean diameter 20-35 $\mathrm{nm}$ for exhaust soot from a medium duty diesel engine at different operating conditions. Such findings are further supported by a study of Lapuerta et al. [8], reporting a mean primary particle diameter of $25 \mathrm{~nm}$ for a light duty diesel. However, the diameters only ranged from 10 to $45 \mathrm{~nm}$. In contrast, a study by Liati et al. [두] found a mean primary particle diameter of $13.7 \mathrm{~nm}$. Interestingly, $60 \%$ of particles measuring below $13 \mathrm{~nm}$. For soot in the lubricating oil of a diesel engine, La Rocca et al. [ [] observed the mean primary particle diameter to be $20.2 \mathrm{~nm}$, similar to exhaust soot. However, the range of diameters was narrower with a span from 10 to only $35 \mathrm{~nm}$. A study by Ferraro et al. [55] reported a mean particle diameter of $25 \mathrm{~nm}$, however, also showed a second distribution around $48 \mathrm{~nm}$, accounting for almost $9 \%$ of particles. Barone et al. [56] assessed primary particles of exhaust soot from a GDI engine. The particle diameters ranged 7-60 $\mathrm{nm}$ with a mode between 20 and $25 \mathrm{~nm}$. Liati et al. [13] observed a similar range of 5-50 nm but with a lower mode between 10 and $15 \mathrm{~nm}$. Gaddam and Vander Wal [12] further reported a diameter range of 7-65nm and mean diameters of $16-25 \mathrm{~nm}$ for GDI soot particles, depending on engine operating conditions. Thus, GDI exhaust soot primary particles appear to be similar to those of diesel engines. While studies on diesel soot-in-oil are already limited, the investigations for GDI soot-in-oil are even scarcer. An initial study by La Rocca et al. [44] showed an extended diameter range of 20-90 nm, with a mean diameter of $36 \mathrm{~nm}$. Although some properties have already been assessed, little quantitative information on primary particles sizes is provided. An overview of the reported findings is presented in Table 1.

This study set out to close the gap in knowledge for GDI soot-in-oil. The concentration of soot in the used lubricating oil samples was established by TGA. Thus, the deposition rate could be assessed by relating the soot content to the sample oil mileage. Agglomerate sizes were determined by means of NTA. Furthermore, TEM imaging was employed to obtain qualitative information of the soot morphology. Carbon particles lacking any apparent long-range order are here presumed to be entirely amorphous. Subsequent quantitative information was gathered by measuring primary particles within the images.

TABLE 1 Reported primary particle diameter ranges, means, and mode as measured from TEM images for diesel and GDI soot obtained from the exhaust gas stream and lubricating oil of the engines. (* bimodal distribution observed)

\begin{tabular}{|c|c|c|c|c|c|}
\hline Reference & Fuel & Origin & Range (nm) & Mean $(\mathrm{nm})$ & Mode $(\mathrm{nm})$ \\
\hline Lee et al. [53] & Diesel & Exhaust & $10-60$ & $28-34$ & $20-40$ \\
\hline Zhu et al. [42] & Diesel & Exhaust & $10-60$ & $19-33$ & $15-25$ \\
\hline Neer and Köylü [ㅁ] & Diesel & Exhaust & - & $20-35$ & - \\
\hline Lapuerta et al. [8] & Diesel & Exhaust & $10-45$ & 25 & $20-25$ \\
\hline Liati et al. [므] & Diesel & Exhaust & $4-36$ & 13.7 & 10 \\
\hline La Rocca et al. [7] & Diesel & Oil & $10-35$ & 20.2 & 20 \\
\hline Ferraro et al. [ㄷ5] & Diesel & Oil & - & $25 / 48^{*}$ & - \\
\hline Barone et al. [드] & GDI & Exhaust & $7-60$ & - & $10-15$ \\
\hline Liati et al. [13] & GDI & Exhaust & $5-50$ & - & $10-15$ \\
\hline Gaddam and Vander Wal [12] & GDI & Exhaust & $7-65$ & $16-25$ & $14-22$ \\
\hline La Rocca et al. [44] & GDI & Oil & $20-90$ & 36 & 32 \\
\hline
\end{tabular}




\section{Experimental}

\section{Sample Collection and Preparation}

Three oil samples were collected from a 1.0L, three-cylinder turbocharged GDI engine. The engine was operated in a passenger car in primarily urban driving conditions with activated start-stop mode. The lubricating oil used was Castrol 5W30. Commercial, EN228 compliant unleaded gasoline with a $95 \mathrm{RON}$ rating and up to $5 \%$ ethanol content was used consistently, as readily available at UK stations. The oil mileage, i.e. mileage since the last oil change, for the samples was $5715 \mathrm{~km}$, $6733 \mathrm{~km}$, and $8488 \mathrm{~km}$. To enable accurate TEM analysis, the soot-in-oil samples were cleaned prior to analysis. The methodology employed in this study was previously established by La Rocca et al. [7] and recently used by Pfau et al. [14]. The oil samples were placed in hermetically sealed centrifuge tubes and diluted with $\mathrm{n}$-heptane. To remove contaminants bonded to the soot particles, the tubes were then placed in an ultrasonic bath at $20^{\circ} \mathrm{C}$ for ten minutes. Subsequent centrifugation in an Eppendorf Centrifuge 5418R at 14,000 rpm (relative centrifugal field value of $16,873 \mathrm{~g}$ ) for $90 \mathrm{~min}$ at $25^{\circ} \mathrm{C}$ separated the solid soot particles from the liquid phase due to their comparatively higher density. Thus, the supernatant oil could be carefully extracted and was then replaced by pure n-heptane. The cleaning cycle was repeated for six rounds, yielding a dilution ratio of approximately $1: 75,000$.

\section{Thermogravimetric Analysis}

An assessment of the soot mass was carried out on a TA Instruments Q500 thermogravimetric analyser, with a resolution of $0.1 \mu \mathrm{g}$. The methodology was adapted from the ASTM D5967-08 test standard and was previously used by La Rocca et al. [57]. $20 \mathrm{mg}$ of the undiluted oil samples were placed in platinum TGA pans and loaded into the instrument chamber. Nitrogen was initially used as purge gas at a flow rate of 100 $\mathrm{ml} / \mathrm{min}$. The sample was isothermally held at room temperature for $20 \mathrm{~min}$ before being heated to $50^{\circ} \mathrm{C}$ at a rate of $5^{\circ} \mathrm{C} / \mathrm{min}$. After a minute of isothermal hold at $50^{\circ} \mathrm{C}$, the sample was heated to $550{ }^{\circ} \mathrm{C}$ at a rate of $50{ }^{\circ} \mathrm{C} / \mathrm{min}$. After one minute of isothermal hold at $550^{\circ} \mathrm{C}$, the sample was heated at a slower rate of $20^{\circ} \mathrm{C} / \mathrm{min}$ to $650^{\circ} \mathrm{C}$. Subsequently, the purge gas was switched to air and the sample further heated at a rate of 20 ${ }^{\circ} \mathrm{C} / \mathrm{min}$ to $750^{\circ} \mathrm{C}$, where it was isothermally held for $5 \mathrm{~min}$.

\section{Nanoparticle Tracking Analysis}

NTA was carried out on a Malvern Nanosight LM14 based in the nmRC at the University of Nottingham, with a laser of $405 \mathrm{~nm}$ wavelength. For the size measurement of soot particles, NTA utilises the principle of Brownian motion. The particles are exposed to a laser beam and the scattered light is recorded by a camera aligned with the beam axis. Particles are identified separately, and their centres subsequently traced for as long as they are visible within the frame and are in focus.
The movement of the particle, or translation diffusion coefficient $D$, is measured on a frame-by-frame basis. The hydrodynamic diameter of the particle $d_{h}$ can subsequently be obtained from the Stokes-Einstein equation:

$$
d_{h}=\frac{k_{B} \cdot T}{3 \cdot \pi \cdot \eta \cdot D}
$$

Where $k_{B}$ is the Boltzmann constant, $T$ the sample temperature in Kelvin and $\eta$ the sample viscosity. Video recordings were obtained using a CCD camera at $30 \mathrm{fps}$ and subsequently processed with the NTA V3.2 software. The temperature of the sample throughout was held at $20^{\circ} \mathrm{C}$ and the reference value of viscosity for this temperature was 0.4 $\mathrm{mPa}$ s. $20 \mu \mathrm{l}$ of the oil sample were diluted in $25 \mathrm{ml}$ $\mathrm{n}$-heptane, yielding a dilution ratio of $1: 1,250$, and then dispersed by vortex mixing for approximately 1 minute. At the dilution ratio used, the effect of soot viscosity is low and can be neglected. Approximately $500 \mu \mathrm{l}$ of the suspension were loaded into the sample chamber. Analysis with a higher dilution of 1:12,500 was attempted, however, a greater contribution from noise was observed due to the reduced number of particles. In addition, recordings of pure $\mathrm{n}$-heptane were taken to rule out any influence by the dilution process. No particles were observed. Therefore, all observed particles in the oil dilution are assumed to be genuine particles of the oil sample itself. The identification and tracking of particles was optimised using a detection threshold value of five and automatic settings for blur size and maximum jump distance. To account for statistical errors, the analysis was carried out in batch series of five recordings of 60 seconds each.

\section{Transmission Electron Microscopy}

TEM imaging was carried out on a JEOL 2100F TEM with a Gatan Orius CCD camera, based in the Nanoscale and Microscale Research Centre ( $\mathrm{nmRC}$ ) at the University of Nottingham. Various magnifications, up to 500,000x, have been used at an incident electron beam voltage of $200 \mathrm{kV}$. Following the dilution cleaning of the oil samples, small amounts of the oil-heptane solution were transferred onto TEM grids. The grids consisted of a copper mesh grid coated with lacey amorphous carbon and graphene oxide support film. Upon deposition, the heptane evaporated in ambient conditions. Subsequently, the grids were washed with diethyl ether to further remove oil contamination and therefore improve image quality $[\underline{7}, \underline{14}, \underline{44}]$.

\section{Results and Discussion}

\section{Thermogravimetric Analysis}

The content of soot in the lubricating oil was identified by TGA. For the three samples, the contents were found to be $0.40,0.42$, and $0.51 \mathrm{wt} \%$ for the 5715,6733 , and $8488 \mathrm{~km}$ samples, respectively (see Figure 1). Clearly, a numerical increase of soot 
FIGURE 1 Soot content measurements by TGA of three GDI oil samples, previously reported soot deposition rate in oil for diesel engines [39], and discovered soot deposition rate in oil for GDI engines.

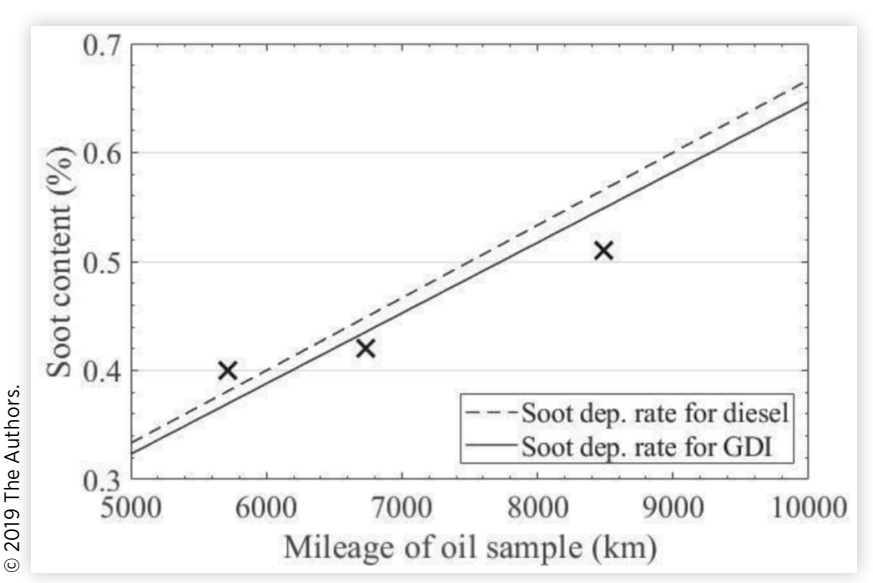

content can be observed with increasing oil mileage. For diesel engines, the deposition rate for soot in the lubricating oil was found to correlate linearly with the oil mileage [38]. A broad study of several diesel soot-in-oil samples by Di Liberto et al. [39] suggested a deposition rate of approximately $1 \mathrm{wt} \%$ per $15,000 \mathrm{~km}$ with a standard deviation $0.4 \mathrm{wt} \%$. Thus, it was attempted to fit a linear deposition rate model for the obtained measurements as well. To the best knowledge of the authors, this is the first correlation of oil mileage and soot deposition in the lubricating oil for a GDI engine. The soot content was scaled from the respective oil mileage to $15,000 \mathrm{~km}$ and subsequently averaged over the three samples. The mean deposition rate was found to be $0.96 \mathrm{wt} \%$, with a standard deviation of $0.08 \mathrm{wt} \%$. While the deposition rate appears to be slightly lower than the diesel model (see Figure 1), the standard deviation is five times lower. This could be due to the limited number of data points included here. The range of vehicles included in the study by Di Liberto et al. [푸] was broader, thus allowing for a more general estimate of the soot deposition rate for diesel engines. The obtained measurements of this study fit within this established diesel model. This agreement suggests that soot accumulation in the lubricating oil is of similar importance for GDI engines as it is for diesel engines. To confirm the observation and establish the quantitative dimension of the deposition rate, further studies of larger scale are required.

\section{Nanoparticle Tracking Analysis}

Measurements of soot agglomerates directly in an oilheptane solutions were obtained by NTA (see Figure 2). The size distribution exhibits an asymmetric shape with particle numbers shifted towards larger sizes from the mode at $100 \mathrm{~nm}$. The mean agglomerate size was found to be $132 \mathrm{~nm}$. On the lower side of the mode, the particle numbers fall sharply, consistent with the expected limit of detection. Additional populations were found at 155 and $241 \mathrm{~nm}$, with $\sim 300 \mathrm{~nm}$ representing an upper size limit for this principle distribution. The inset in Figure 2 shows an enlarged view
FIGURE 2 Size distribution and volume concentration of soot particles in used lubricating oil measured by NTA.

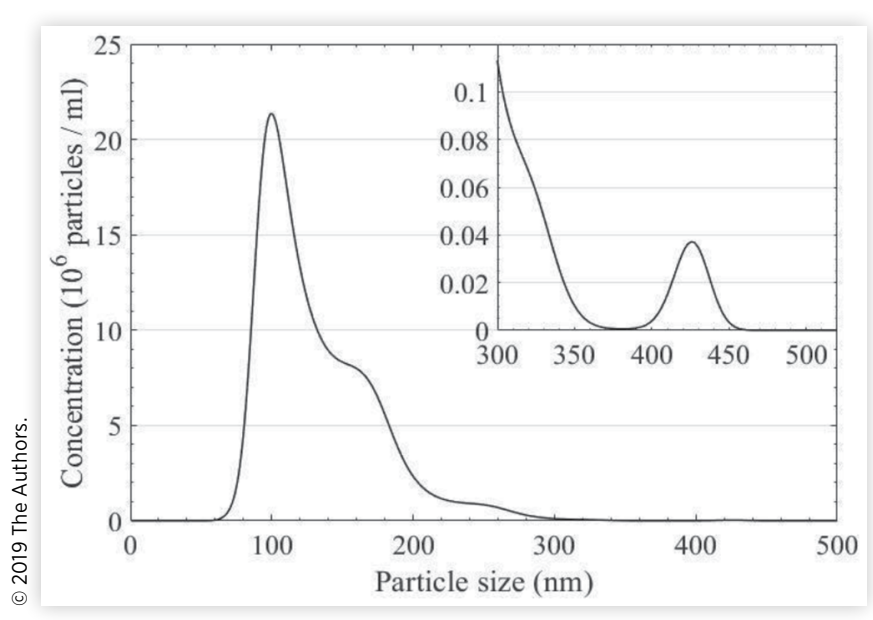

of the size range of $300-500 \mathrm{~nm}$. Almost no agglomerates are present in the range of 350-400 $\mathrm{nm}$; however, a second mode at $426 \mathrm{~nm}$ becomes apparent. Nevertheless, the concentration is significantly lower than the first mode by three orders of magnitude, i.e. $3.7 \mathrm{e}+04$ compared to $2.2 \mathrm{e}+07$. No such feature could be observed for lower particle sizes, i.e. below $100 \mathrm{~nm}$.

As NTA is a novel technique and has only been used in a few studies, the obtained measurements are compared with literature based on dynamic light scattering (DLS) in addition studies using NTA. An initial study by La Rocca et al. [57] compared DLS and NTA measurements for soot-in-oil samples of two diesel engines. The NTA values were found to be lower than the values in this study with mean particle sizes of 115-126 $\mathrm{nm}$ and main modes at 98-110 $\mathrm{nm}$. The results from the DLS analysis differed only by few nanometres from the NTA findings. In a subsequent study, a similar second peak at higher agglomerate sizes was observed for diesel sootin-oil [52]. In a comparative study, Key et al. [43] measured agglomerate sizes of 91.8 and $116.8 \mathrm{~nm}$ for two types of carbon black, as well as $96.5 \mathrm{~nm}$ for diesel soot-in-oil. Moreover, both studies showed that the dimensions obtained by NTA correlated well with the skeleton length of the agglomerates as observable in TEM images. Kim et al. [됴] used 16 oil formulations in two diesel engines for $25 \mathrm{~h}$ and subsequently analysed the soot-laden oil samples by DLS. The average agglomerate size ranged from 98.4 to $163.8 \mathrm{~nm}$ among the oils. However, it should be noted that the analysis in the study showed a high variation, i.e. duplicate runs for different batches of the same sample yielded average values 122.2 and $163.8 \mathrm{~nm}$. Liu et al. [59] operated diesel engines with lubricating oils of different formulations. DLS measurements found mean particle sizes ranging from 111 to $266 \mathrm{~nm}$, depending on oil formulation and temperature at which the measurement was carried out. Overall, it can be noted that the range of NTA and DLS measurements for diesel soot is very broad. Here, the observed mean and mode values lie within this range. However, as the technique appears to be sensitive to engine parameters and measurement conditions, more information could be obtained by direct comparative assessment of samples. 


\section{Transmission Electron Microscopy}

The GDI soot samples exhibit a diverse morphology. Some soot agglomerates of several primary particles were observed with fractal shapes (see Figure 3). The morphology of the agglomerates could have been influenced by the centrifugation of the sample preparation process, albeit ultrasonic bathing allows for particle breakup. The nanostructure and size of primary particles remains unaffected [7]. Consequently, no measurements of agglomerates were taken from the TEM images; agglomerate size distribution was assessed only by NTA. Key et al. [43] and La Rocca et al. [2] demonstrated that NTA measurements correlate well to agglomerate skeleton length.

To assess the similarity to other types of soot quantitatively, the size of 171 primary particles was measured (see Figure 4). Two perpendicular measurements were taken for each particle and the average ratio between the two values

FIGURE 3 TEM images of fractal soot agglomerates of several primary particles.

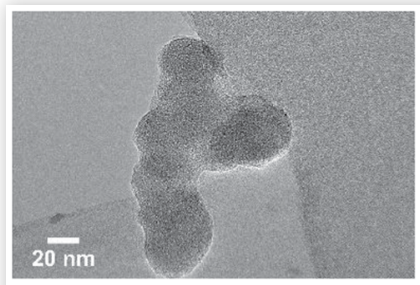

a)

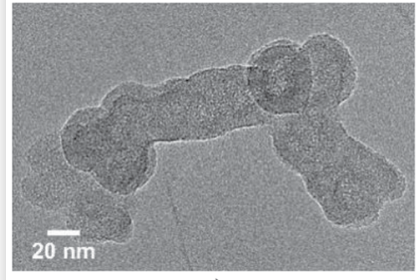

c)

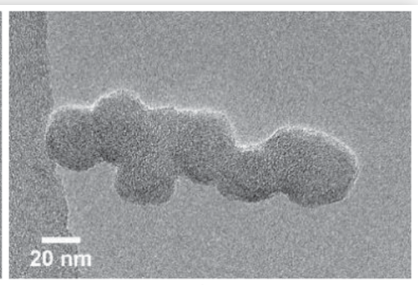

b)

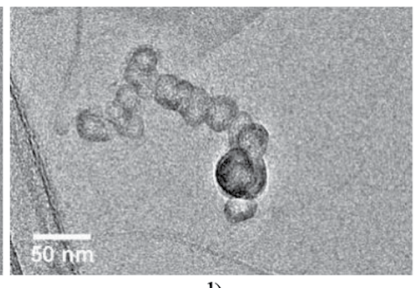

d)
FIGURE 4 Frequency distribution of the primary particle diameter as measured from agglomerates in TEM images.

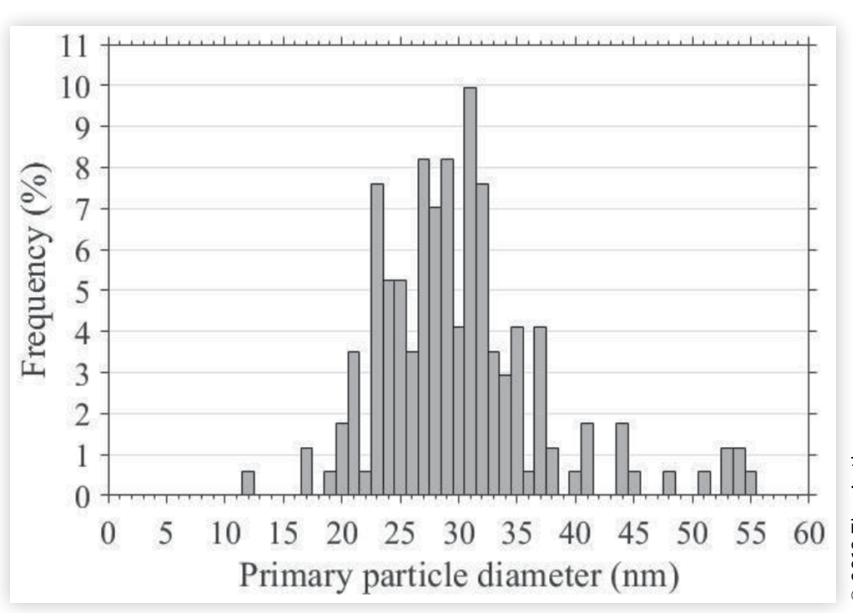

was 1.09 (standard deviation of 0.08 ). The ratio indicates that the particles are on average slightly oval, however, still close to a spherical, round shape. Thus, the arithmetic mean between the two measurements is used as diameter for each particle. For the present samples, the diameters ranged from 12 to $55 \mathrm{~nm}$, with a mode at $31 \mathrm{~nm}$ and a mean of $30 \mathrm{~nm}$. The range is lower than previous findings for GDI soot-in-oil, i.e. 20-90 nm [44]. However, the measurements are similar to findings for GDI exhaust soot samples that exhibited primary particle diameters from as low as 5 [13] up to $65 \mathrm{~nm} \mathrm{[12].}$ Similarly, the mean value better fits with the findings for exhaust soot than for soot-in-oil. In contrast, the mode found here is in line with previous findings for GDI soot-in-oil, while lower modes from $10[13, \underline{56}]$ to $22 \mathrm{~nm}[12]$ were observed for GDI exhaust soot.

Qualitative assessment of the primary particles showed a prevalence of the typical core-shell nanostructure (see Figure $\underline{5 a, b})$. In Figure $5 \mathrm{c}$ both amorphous core and graphitic shell are marked as well as an unusual surrounding amorphous

FIGURE 5 Soot primary particles (a,b). Marked primary particle with central core, graphitic shell and surrounding amorphous layer (c). Enlargements $A$ and $B$ show details of nanostructure (d,e).

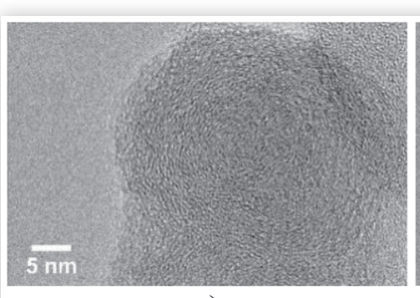

a)

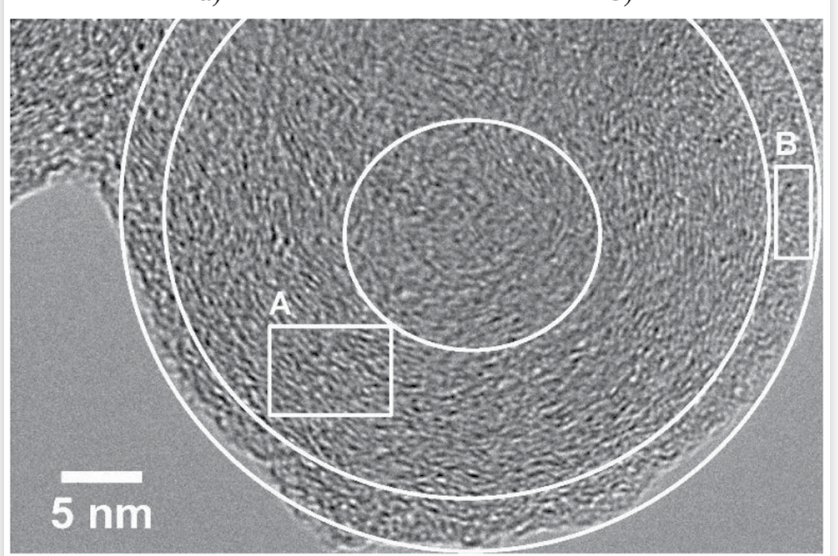

c)

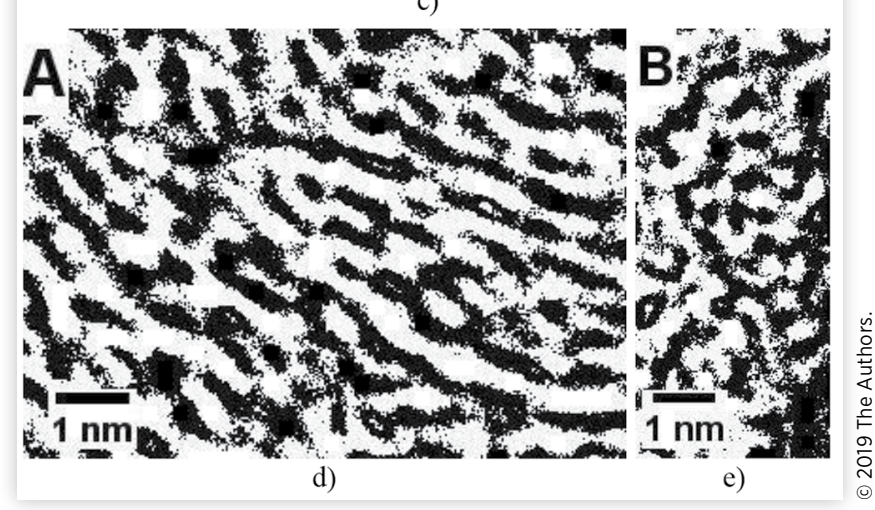


layer. This observation is in line with a previous study by La Rocca et al. [44]. Details of the particle nanostructure are presented in Figure 5d,e. Both images were contrast enhanced and binarised, to improve the visibility of the structure. The surrounding layer shows a significantly lower degree of order compared to the graphitic shell. The subsequent higher amount of edge sites is likely to increase overall reactivity, as reported by Vander Wal and Tomasek [무].

Moreover, entirely amorphous aggregates were present in all samples. The observed structures lack any apparent long range-order and are thus assumed to be amorphous. Some of these particles exhibit distinctive particle edges (see Figure 6a,b), while others appear partly "sludge-like" and blend partly with the carbon background of the TEM grid (see Figure 6c,d). This observation was first made by Uy et al. [10] but also confirmed in a previous work on the same engine as used in this study [14]. While the former found the amorphous particles to be particularly prone to decomposition, no such decomposition could be observed here even after prolonged exposure under the electron beam of the microscope. The nanostructure of the amorphous particles exhibits more reactive edge sites compared to typical core-shell soot particles. This difference can also be observed in the additional amorphous shell surrounding such particles, as displayed in Figure $5 \mathrm{~d}$,e. Antusch et al. [15] suggested different nanostructures to cause altered reactivity of the soot. This was subsequently supported by studies conducted by Vander Wal and Tomasek [60] as well as Alfè et al. [61]. This would further suggest a higher degree of interaction with the lubricating oil. As a result, the effectiveness of oil additives could be diminished and wear thus be enhanced [16].

Some of the particles further exhibited crystalline regions (see Figure 7), which were found to promote wear in engines [62]. Such behaviour was observed by Sharma et al. [주 for diesel engines particularly with higher engine age. Several studies suggested that the crystalline structures could stem from wear elements and oil additives $[\underline{10}, \underline{14}, \underline{40}]$. Consequently, understanding of soot properties is required to predict and manage the interaction of soot particles with the lubricating oil.

FIGURE 6 Distinctive $(\mathrm{a}, \mathrm{b})$ and sludge-like $(\mathrm{c}, \mathrm{d})$ amorphous particles.

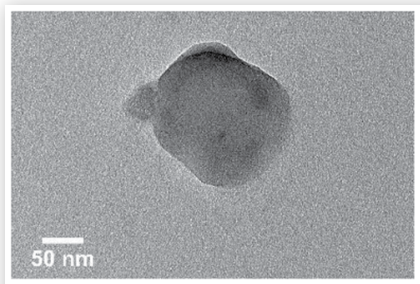

a)

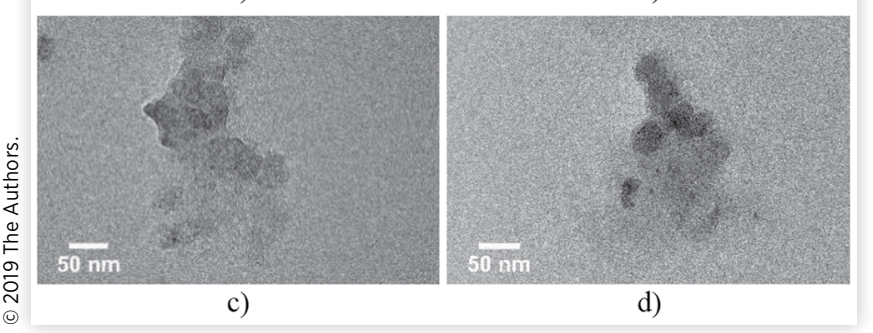

\section{FIGURE 7 Crystalline regions within amorphous particles.}

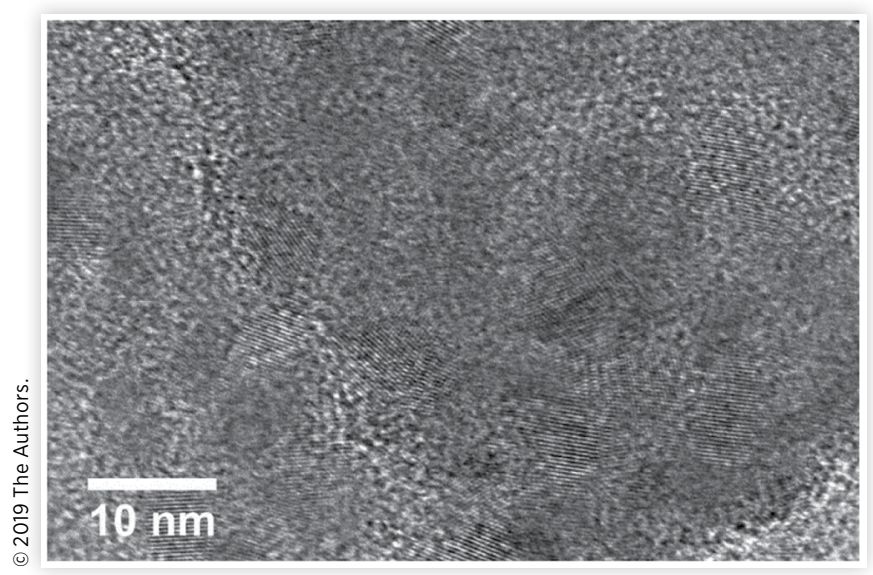

The results reported in this work highlight that soot deposition to the engine oil experienced in the turbocharged gasoline direct injection engine used in this study shows similar levels as per the diesel soot-in-oil levels measured by Di Liberto et al. [39] and Sharma et al. [누].

It is well know that soot can compromise engine durability due to wear $[\underline{22}, \underline{25}]$ and can potentially promote wear between pins and bushings leading to chain elongation [26]. Another undesired effect of soot-in-oil is related to lubricant thickening which can results in pumpability issues due to the altered viscosity [27]. These well-known soot-related issues of diesel engines can now be of relevance for the modern GTDI engines, so further research in this area is required to understand the extent of the problem for these new engines. Another potential threat is related to the different nanostructure characteristics shown by the soot nanoparticles formed in the gasoline engines. Amorphous aggregates were present in all samples and with nanoparticles shown a less graphitic structure with more defects. This was also noticed by Liati et al. [13]. Pfau et al. [14] confirmed such differences, pointing out that GDI soot is more reactive than carbon black and diesel soot. These nanostructure characteristics affect the reactivity of soot [15] but also impede the effectiveness of oil additives as established by Esangbedo et al. [16].

\section{Conclusions}

Three soot-in-oil samples were taken from a GDI engine after different oil mileages, and comprehensively analysed. The findings from this work suggest that soot-in-oil levels measured in GDI engines can be comparable to those of diesel engines; likewise agglomerate and primary size distributions. However, the particle nanostructure can differ significantly with some entirely amorphous particles observed. This could imply a different interaction with the lubricating oil and subsequently altered wear behaviour of GDI soot. In particular, the work carried out on here has led to the following conclusions:

- The soot content in the oil samples was assessed by TGA. A linear trend model was fitted, showing a deposition rate of $0.96 \mathrm{wt} \%$ per $15,000 \mathrm{~km}$ with a standard deviation 
of $0.08 \mathrm{wt} \%$. The model is in agreement with linear deposition rate models for diesel engines. Thus, it is suggested that soot in the lubricating oil is of similar importance for GDI engines.

- Analysis of agglomerate sizes was carried out by NTA and revealed an asymmetric distribution. The principle population was observed with a modal value of $100 \mathrm{~nm}$, with additional, smaller populations at 155 and $241 \mathrm{~nm}$. While almost no particles were observed in the range of $350-400 \mathrm{~nm}$, a further population was found at $426 \mathrm{~nm}$. However, particle numbers this additional population were lower by three magnitudes compared to those in the range of $\sim 100-350 \mathrm{~nm}$.

- TEM imaging revealed a diverse appearance of the soot. Both typical soot particles in agglomerates and entirely amorphous particles were observed. While the former exhibited core-shell structures, the latter showed no apparent long-range order.

- Primary particles were subsequently measured as captured in the TEM images. A unimodal size distribution was observed, with a mode at $31 \mathrm{~nm}$ and mean of $30 \mathrm{~nm}$.

Future work will encompass the verification of the suggested soot deposition behaviour for GDI engines. Further, a universal deposition rate model should be established. This could be facilitated in a large-scale study including a broad range of vehicles and mileages. The effects of both engine and vehicle specifications as well as operating conditions would therewith be averaged. This would provide a comprehensive understanding of soot deposition and allow for the design of effective lubricating oils and technical guidelines. Moreover, detailed engine dynamometer tests could be carried out to further establish the effect of individual engine parameters on the soot deposition rate.

\section{References}

1. Zhao, F., Lai, M.C., and Harrington, D.L., "Automotive Spark-Ignited Direct-Injection Gasoline Engines," Prog. Energy Combust. Sci. 25(5):437-562, 1999, doi:10.1016/S0360$\underline{1285(99) 00004-0 .}$.

2. Li, Y., Xue, J., Johnson, K., Durbin, T. et al., "Determination of Suspended Exhaust PM Mass for Light-Duty Vehicles," SAE Technical Paper 2014-01-1594, 2014, doi:10.4271/201401-1594.

3. Su, J., Lin, W., Sterniak, J., Xu, M. et al., "Particulate Matter Emission Comparison of Spark Ignition Direct Injection (SIDI) and Port Fuel Injection (PFI) Operation of a Boosted Gasoline Engine," Journal of Engineering for Gas Turbines and Power 136(9), 2014, doi:10.1115/1.4027274.

4. Heywood, J.B., Internal Combustion Engine Fundamentals (New York: McGraw-Hill, 1988).

5. Bockhorn, H., "A Short Introduction to the Problem Structure of the Following Parts," . In: Soot Formation in Combustion: Mechanisms and Models. (Berlin, Heidelberg, Springer, 1994), 3-7, doi:10.1007/978-3-642-85167-4_1.
6. Richter, H. and Howard, J.B., "Formation of Polycyclic Aromatic Hydrocarbons and their Growth to Soot - A Review of Chemical Reaction Pathways," , 2000, doi:10.1016/ S0360-1285(00)00009-5.

7. La Rocca, A., Di Liberto, G., Shayler, P.J., and Fay, M.W., "The Nanostructure of Soot-in-Oil Particles and Agglomerates from an Automotive Diesel Engine," Tribol. Int. 61:80-87, 2013, doi:10.1016/j.triboint.2012.12.002.

8. Lapuerta, M., Martos, F.J., and Herreros, J.M., "Effect of Engine Operating Conditions on the Size of Primary Particles Composing Diesel Soot Agglomerates," J. Aerosol Sci. 38(4):455-466, 2007, doi:10.1016/j.jaerosci.2007.02.001.

9. Neer, A. and Köylü, U.O., "Effect of Operating Conditions on the Size, Morphology, and Concentration of Submicrometer Particulates Emitted from a Diesel Engine," Combust. Flame 146(1-2):142-154, 2006, doi:10.1016/j.combustflame.2006.04.003.

10. Uy, D., Ford, M.A., Jayne, D.T., O’Neill, A.E. et al., "Characterization of Gasoline Soot and Comparison to Diesel Soot: Morphology, Chemistry, and Wear," Tribol. Int. 80:198-209, 2014, doi:10.1016/j.triboint.2014.06.009.

11. An, Y., Teng, S., Pei, Y., Qin, J. et al., “An Experimental Study of Polycyclic Aromatic Hydrocarbons and Soot Emissions from a GDI Engine Fueled with Commercial Gasoline," Fuel 164:160-171, 2016, doi:10.1016/j.fuel.2015.10.007.

12. Gaddam, C.K. and Vander Wal, R.L., "Physical and Chemical Characterization of SIDI Engine Particulates," Combust. Flame 160(11):2517-2528, 2013, doi:10.1016/j. combustflame.2013.05.025.

13. Liati, A., Schreiber, D., Dimopoulos Eggenschwiler, P., Arroyo Rojas Dasilva, Y. et al., "Electron Microscopic Characterization of Soot Particulate Matter Emitted by Modern Direct Injection Gasoline Engines," Combust. Flame 166:307-315, 2016, doi:10.1016/j.combustflame.2016.01.031.

14. Pfau, S.A., La Rocca, A., Haffner-Staton, E., Rance, G.A. et al., "Comparative Nanostructure Analysis of Gasoline Turbocharged Direct Injection and Diesel Soot-in-Oil with Carbon Black," Carbon 139:342-352, 2018, doi:10.1016/j. carbon.2018.06.050.

15. Antusch, S., Dienwiebel, M., Nold, E., Albers, P. et al., "On the Tribochemical Action of Engine Soot," Wear 269(1-2): 1-12, 2010, doi:10.1016/j.wear.2010.02.028.

16. Esangbedo, C., Boehman, A.L., and Perez, J.M., "Characteristics of Diesel Engine Soot that Lead to Excessive Oil Thickening," Tribol. Int. 47:194-203, 2012, doi:10.1016/j. triboint.2011.11.003.

17. Rissler, J., Swietlicki, E., Bengtsson, A., Boman, C. et al., "Experimental Determination of Deposition of Diesel Exhaust Particles in the Human Respiratory Tract," J. Aerosol Sci. 48:18-33, 2012, doi:10.1016/j.jaerosci.2012.01.005.

18. Broday, D.M. and Rosenzweig, R., "Deposition of Fractallike Soot Aggregates in the Human Respiratory Tract," J. Aerosol Sci. 42(6):372-386, 2011, doi:10.1016/j. jaerosci.2011.03.001.

19. Pedata, P., Stoeger, T., Zimmermann, R., Peters, A. et al., "Are we Forgetting the Smallest, Sub $10 \mathrm{Nm}$ Combustion Generated Particles?” Part. Fibre Toxicol. 12(34), 2015, doi:10.1186/s12989-015-0107-3.

20. Baldauf, R.W., Devlin, R.B., Gehr, P., Giannelli, R. et al., "Ultrafine Particle Metrics and Research Considerations: 
Review of the 2015 UFP Workshop," Int. J. Environ. Res. Public Health 13(11), 2016, doi:10.3390/ijerph13111054.

21. Lahouij, I., Dassenoy, F., Vacher, B., Sinha, K. et al., "Understanding the Deformation of Soot Particles/ Agglomerates in a Dynamic Contact: Tem In Situ Compression and Shear Experiments," Tribol. Lett. 53(1):9199, 2014, doi:10.1007/s11249-013-0246-3.

22. Green, D.A. and Lewis, R., "The Effects of SootContaminated Engine Oil on Wear and Friction: A Review," Proc. Inst. Mech. Eng. Part D J. Automob. Eng. 222(9):16691689, 2008, doi:10.1243/09544070JAUTO468.

23. Li, S., Csontos, A.A., Gable, B.M., Passut, C.A. et al., "Wear in Cummins M-11 / EGR Test Engines," SAE Technical Paper 2002-01-1672, 2002.

24. Gautam, M., Chitoor, K., and Balla, S., "Contribution of Soot Contaminated Oils to Wear-Part II," SAE Technical Paper 1999-01-1519, 1999, doi:10.4271/1999-01-1519.

25. Sato, H., Tokuoka, N., Yamamoto, H., and Sasaki, M., "Study on Wear Mechanism by Soot Contaminated in Engine Oil (First Report: Relation between Characteristics of Used Oil and Wear)," SAE Technical Paper 1999-01-3573, 1999, doi:10.4271/1999-01-3573.

26. Polat, O., Ebrinc, A.A., Ozen, C., and Akca, S., "Timing Chain Wear Assessment with Different Type of Oils," SAE Technical Paper 2009-01-0198, 2009, doi:10.4271/2009-01-0198.

27. Stehouwer, D.M., Shank, G., Herzog, S.N., Hyndman, C.W. et al., "Sooted Diesel Engine Oil Pumpability Studies as the Basis of a New Heavy Duty Diesel Engine Oil Performance Specification," SAE Technical Paper 2002-01-1671, 2002, doi:10.4271/2002-01-1671.

28. Covitch, M.J., Humphrey, B.K., and Ripple, D.E., "Oil Thickening in the Mack T-7 Engine Test-Fuel Effects and the Influence of Lubricant Additives on Soot Aggregation, SAE Technical Paper 852126,", 1985, doi:10.4271/852126.

29. Berbezier, I., Martin, J.M., and Kapsa, P., "The Role of Carbon in Lubricated Mild Wear,” Tribol. Int. 19(3):115-122, 1986, doi:10.1016/0301-679X(86)90016-2.

30. Mainwaring, R., "Soot and Wear in Heavy Duty Diesel Engines," SAE Technical Paper 971631, 1997, doi:10.4271/971631.

31. Bardasz, E.A., Cowling, S.V., Ebeling, V.L., George, H.F. et al., "Understanding Soot Mediated Oil Thickening through Designed Experimentation - Part 1: Mack EM6-287, GM 6.2L,” SAE Technical Paper 952527, 1995, doi:10.4271/952527.

32. Clague, A.D.H., Donnet, J.B., Wang, T.K., and Peng, J.C.M., "A Comparison of Diesel Engine Soot with Carbon Black," Carbon 37(10):1553-1565, 1999, doi:10.1016/S00086223(99)00035-4.

33. Salamanca, M., Agudelo, J.R., Mondragón, F., and Santamaría, A., "Chemical Characteristics of the Soot Produced in a High-Speed Direct Injection Engine Operated with Diesel/Biodiesel Blends," Combust. Sci. Technol. 184(7):1179-1190, 2012, doi:10.1080/00102202.2012.664007.

34. Bredin, A., Larcher, A.V., and Mullins, B.J., "Thermogravimetric Analysis of Carbon Black and Engine Soot - Towards a more Robust Oil Analysis Method," Tribol. Int. 44(12):16421650, 2011, doi:10.1016/j.triboint.2011.06.002.

35. Yehliu, K., Vander Wal, R.L., Armas, O., and Boehman, A.L., "Impact of Fuel Formulation on the Nanostructure and

(c) 2019 The Authors.
Reactivity of Diesel Soot," Combust. Flame 159(12):35973606, 2012, doi:10.1016/j.combustflame.2012.07.004.

36. Mullins, G. and Truhan, J., "Measurement of Semi-Volatiles in Used Natural Gas Engine Oil Using Thermogravimetric Analysis," Int. J. Engine Res. 8(5):439-448, 2007, doi:10.1243/1 4680874JER00907.

37. Gautam, M., Durbha, M., Chitoor, K., Jaraiedi, M. et al., "Contribution of Soot Contaminated Oils to Wear," SAE Technical Paper 981406, 1998, doi:10.4271/981406.

38. Lockwood, F.E., Zhang, Z.G., Choi, S.U.S., and Yu, W., "Effect of Soot Loading on the Thermal Characteristics of Diesel Engine Oils," SAE Technical Paper 2001-01-1714, 2001, doi:10.4271/2001-01-1714.

39. Di Liberto, G., La Rocca, A., and Shayler, P., "Computational Analysis of the Influence of Exhaust Gas Recirculation on the Rate of Soot Transfer to Lubricating Engine Oil," FISITA Technical Paper F2016-ESYG-020, in 36th FISITA World Automotive Congress, Korea, Sep. 26-30, 2016.

40. Sharma, V., Uy, D., Gangopadhyay, A., O’Neill, A. et al., "Structure and Chemistry of Crankcase and Exhaust Soot Extracted from Diesel Engines," Carbon 103:327-338, 2016, doi:10.1016/j.carbon.2016.03.024.

41. Zhang, R. and Kook, S., "Influence of Fuel Injection Timing and Pressure on In-Flame Soot Particles in an AutomotiveSize Diesel Engine," Environ. Sci. Technol. 48(14):8243-8250, 2014, doi:10.1021/es500661w.

42. Zhu, J., Lee, K.O., Yozgatligil, A., and Choi, M.Y., "Effects of Engine Operating Conditions on Morphology, Microstructure, and Fractal Geometry of Light-Duty Diesel Engine Particulates," Proc. Combust. Inst. 30(2):2781-2789, 2005, doi:10.1016/j.proci.2004.08.232.

43. Key, S., La Rocca, A., Fay, M., Rance, G. et al., "Morphological Characterisation of Diesel Soot in Oil and the Associated Extraction Dependence," SAE Technical Paper 2018-01-0935, 2018, doi:10.4271/2018-01-0935.

44. La Rocca, A., Bonatesta, F., Fay, M.W., and Campanella, F., "Characterisation of Soot in Oil from a Gasoline Direct Injection Engine Using Transmission Electron Microscopy," Tribol. Int. 86:77-84, 2015, doi:10.1016/j.triboint.2015.01.025.

45. Martos, F.J., Lapuerta, M., Expósito, J.J., and SanmiguelRojas, E., "Overestimation of the Fractal Dimension from Projections of Soot Agglomerates," Powder Technol. 311:528536, 2017, doi:10.1016/j.powtec.2017.02.011.

46. Orhan, O., Haffner-Staton, E., La Rocca, A., and Fay, M., "Characterisation of Flame-Generated Soot and Soot-in-Oil Using Electron Tomography Volume Reconstructions and Comparison with Traditional 2D-TEM Measurements," Tribol. Int. 104:272-284, 2016, doi:10.1016/j.triboint.2016.09.015.

47. La Rocca, A., Campbell, J., Fay, M.W., and Orhan, O., "SootIn-Oil 3D Volume Reconstruction through the Use of Electron Tomography: An Introductory Study," Tribol. Lett. 61(1), 2016, doi:10.1007/s11249-015-0625-z.

48. Haffner-Staton, E., La Rocca, A., and Fay, M.W., "Progress towards a Methodology for High Throughput 3D Reconstruction of Soot Nanoparticles Via Electron Tomography," J. Microsc., 2018, doi:10.1111/jmi.12680.

49. Lee, K.O., Seong, H., Sakai, S., Hageman, M. et al., “Detailed Morphological Properties of Nanoparticles from Gasoline Direct Injection Engine Combustion of Ethanol Blends," 
SAE Technical Paper 2013-24-0185, 2013, doi:10.4271/201324-0185.

50. Wang, C., Xu, H., Herreros, J.M., Wang, J. et al., "Impact of Fuel and Injection System on Particle Emissions from a GDI Engine," Appl. Energy 132:178-191, 2014, doi:10.1016/j. apenergy.2014.06.012.

51. Graves, B.M., Koch, C.R., and Olfert, J.S., "Morphology and Volatility of Particulate Matter Emitted from a Gasoline Direct Injection Engine Fuelled on Gasoline and Ethanol Blends," J. Aerosol Sci. 105:166-178, 2017, doi:10.1016/j. jaerosci.2016.10.013.

52. La Rocca, A., Di Liberto, G., Shayler, P.J., Parmenter, C.D.J. et al., "Application of Nanoparticle Tracking Analysis Platform for the Measurement of Soot-in-Oil Agglomerates from Automotive Engines," Tribol. Int. 70:142-147, 2014, doi:10.1016/j.triboint.2013.09.018.

53. Lee, K.O., Cole, R., Sekar, R., Choi, M.Y. et al., "Morphological Investigation of the Microstructure, Dimensions, and Fractal Geometry of Diesel Particulates," Proc. Combust. Inst. 29(1):647-653, 2002, doi:10.1016/S1540-7489(02)80083-9.

54. Liati, A., Dimopoulos Eggenschwiler, P., Schreiber, D., Zelenay, V. et al., "Variations in Diesel Soot Reactivity along the Exhaust after-Treatment System, Based on the Morphology and Nanostructure of Primary Soot Particles," Combust. Flame 160(3):671-681, 2013, doi:10.1016/j. combustflame.2012.10.024.

55. Ferraro, G., Fratini, E., Rausa, R., Fiaschi, P. et al., "Multiscale Characterization of some Commercial Carbon Blacks and Diesel Engine Soot," Energy Fuels 30(11):98599866, 2016, doi:10.1021/acs.energyfuels.6b01740.

56. Barone, T.L., Storey, J.M.E., Youngquist, A.D., and Szybist, J.P., "An Analysis of Direct-Injection Spark-Ignition (DISI) Soot Morphology," Atmos. Environ. 49:268-274, 2012, doi:10.1016/j.atmosenv.2011.11.047.

57. La Rocca, A., Di Liberto, G., Shayler, P., Parmenter, C. et al., "A Novel Diagnostics Tool for Measuring Soot Agglomerates Size Distribution in Used Automotive Lubricant Oils," SAE Int. J. Fuels Lubr. 7(1):301-306, 2014, doi:10.2307/26273078.

58. Kim, C., Passut, C.A., and Zang, D.M., "Relationships Among Oil Composition, Combustion-Generated Soot, and Diesel Engine Valve Train Wear," SAE Technical Paper 922199, 1992, doi:10.4271/922199.

59. Liu, C., Nemoto, S., and Ogano, S., "Effect of Soot Properties in Diesel Engine Oils on Frictional Characteristics," Tribol. Trans. 46(1):12-18, 2003, doi:10.1080/10402000308982593.

60. Vander Wal, R.L. and Tomasek, A.J., "Soot Oxidation: Dependence upon Initial Nanostructure," Combust. Flame 134(1-2):1-9, 2003, doi:10.1016/S0010-2180(03)00084-1.

61. Alfè, M., Apicella, B., Barbella, R., Rouzaud, J.N. et al., "Structure-Property Relationship in Nanostructures of Young and Mature Soot in Premixed Flames," Proc. Combust. Inst. 32(1):697-704, 2009, doi:10.1016/j. proci.2008.06.193.
62. Patel, M. and Aswath, P.B., "Morphology, Structure and Chemistry of Extracted Diesel Soot: Part II: X-Ray Absorption near Edge Structure (XANES) Spectroscopy and High Resolution Transmission Electron Microscopy," Tribol. Int. 52:17-28, 2012, doi:10.1016/j.triboint.2012.02.022.

63. Sharma, V., Bagi, S., Patel, M., Aderniran, O. et al., "Influence of Engine Age on Morphology and Chemistry of Diesel Soot Extracted from Crankcase Oil," Energy Fuels 30(3):2276-2284, 2016, doi:10.1021/acs.energyfuels.5b02512.

\section{Contact Information}

Correspondence to: Dr Antonino La Rocca

Associate Professor

Powertrain Research Group

Department of Mechanical Materials and

Manufacturing Engineering

The University of Nottingham

Nottingham

NG7 2RD U.K.

antonino.larocca@nottingham.ac.uk

\section{Acknowledgments}

This work was supported by the Engineering and Physical Sciences Research Council through the scholarship provided by EPSRC DTG Centre in Complex Systems and Processes for Ephraim Haffner-Staton and the scholarship provided by EPSRC Thematic Programme in Low-Dimensional Materials and Interfaces for Sebastian Pfau [grant numbers EP/ M506588/1 and EP/N50970X/1 respectively]. The authors thank the Nanoscale and Microscale Research Centre (nmRC) for providing access to instrumentation.

\section{Definitions/Abbreviations}

D - Translation diffusion coefficient

$\mathbf{d}_{\mathrm{h}}$ - Hydrodynamic diameter

DLS - Dynamic Light Scattering

GDI - Gasoline Direct Injection

$\mathbf{k}_{\mathrm{B}}$ - Boltzmann constant

nmRC - Nanoscale and Microscale Research Centre

NTA - Nanoparticle Tracking Analysis

PAH - Polycyclic Aromatic Hydrocarbons

PFI - Port Fuel Injection

T - Temperature

TEM - Transmission Electron Microscopy

TGA - Thermogravimetric Analysis

$\eta$ - Viscosity

(c) 2019 The Authors. Published by SAE International. This Open Access article is published under the terms of the Creative Commons Attribution License (http:// creativecommons.org/licenses/by/4.0/), which permits distribution, and reproduction in any medium, provided that the original author(s) and the source are credited. 